\title{
From Division, To Relation
}

\section{Katherine Tran}

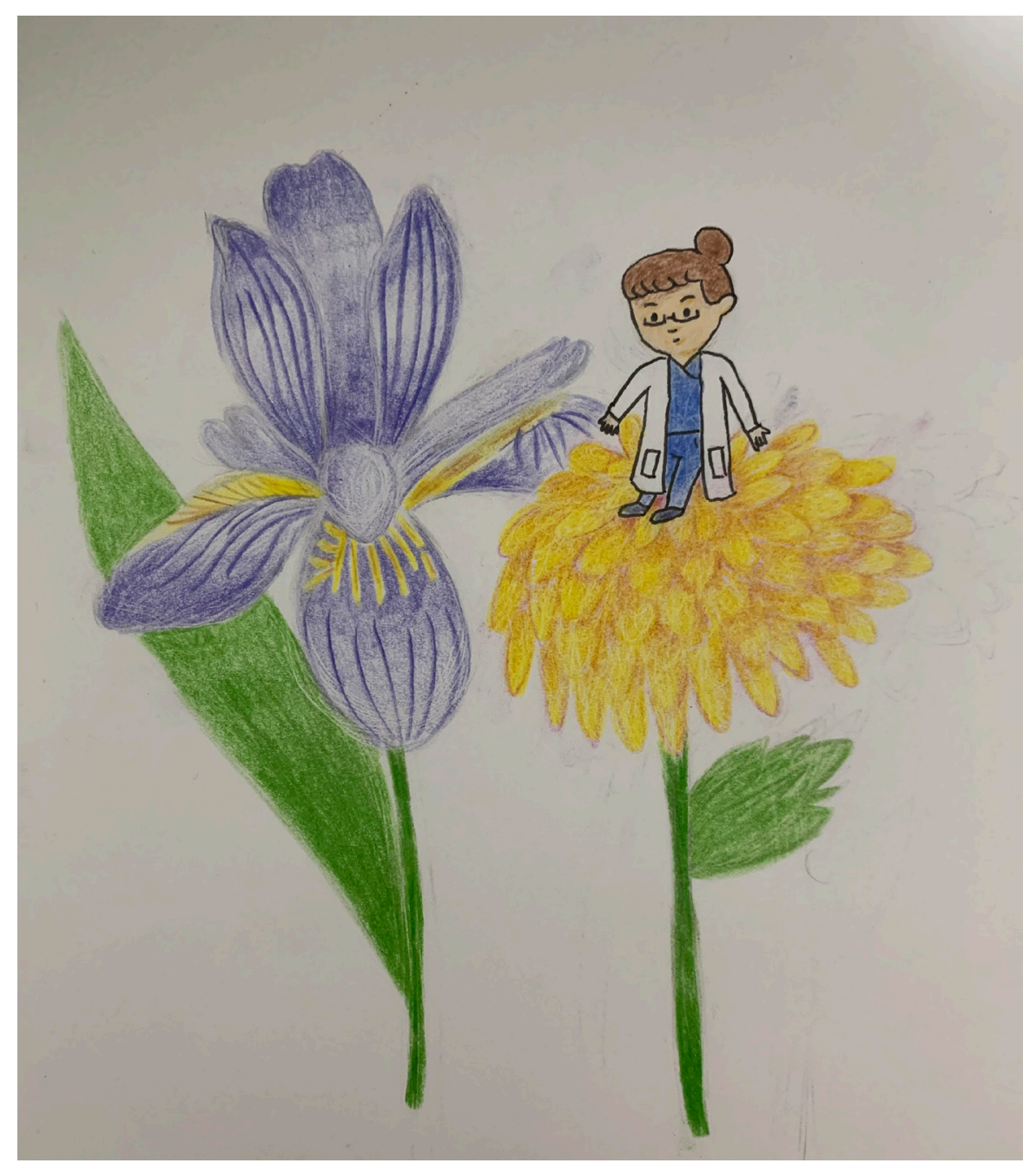

Health professionals have to treat many patients from in various situations. Whether in cases of chronic diseases or, acute diseases, or when a patient's life is on the line, health professionals are always there to aid their patients. Although, health professionals have to face what comes their way if something happens to their patients. Two flowers represent the two types of encounter health professionals have withs their patients. The iris (left) symbolizes "hope,", which is what health professionals strive for their patients to have. To hope for a healthier life is mainly what health professionals want for their patients. The gold chrysanthemum (right) symbolizes "death", one of the most difficult situations that health professionals have to face. This results with health professionals to have many emotions when it comes to these events come upon their patients. There are many obstacles that health professionals have to face. Whether in the successful or in the toughest times, one thing such obstacles have in common is the providence of love and support from health professionals who are willing to give every minute of their time for their patients.

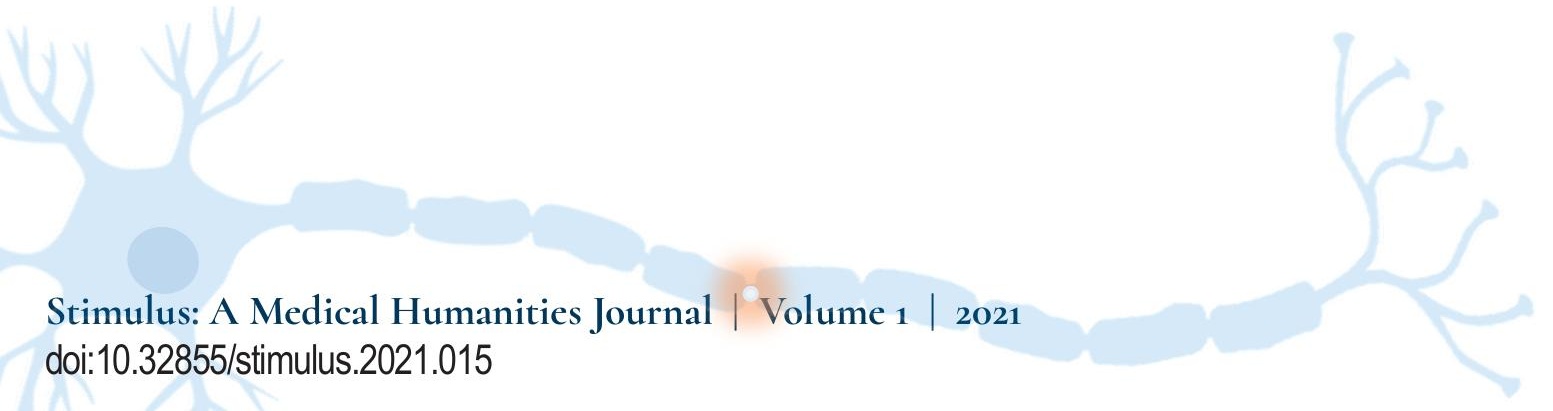

